\title{
EVALUASI KESESUAIAN LAHAN UNTUK TANAMAN HORTIKULTURA DI LAHAN SEKOLAH TINGGI THEOLOGIA MALUKU DUSUN KATE-KATE DESA HUNUTH KECAMATAN TELUK AMBON
}

\author{
Evaluation of Land Suitability for Horticultural Crops in Maluku Theology School Yard in Kate- \\ Kate area, Hunut Village, Ambon Bay Subdistrict
}

\section{Meilany Lenussa ${ }^{1}$, Elisa J. Gaspersz ${ }^{2, *}$, dan Rudy Soplanit ${ }^{2}$}

\author{
${ }^{1}$ Program Studi Agroekoteknologi, Jurusan Budidaya Pertanian, Fakultas Pertanian, Universitas Pattimura \\ ${ }^{2}$ Jurusan Budidaya Pertanian, Fakultas Pertanian, Universitas Pattimura \\ Jl. Ir. M. Putuhena, Kampus Poka, Ambon 97233 \\ *Penulis korespondensi: E-mail: elisa.gaspersz@faperta.unpatti.ac.id
}

\begin{abstract}
The study was conducted from October to November 2016 in Maluku Theology School Yard in Kate-Kate, Hunuth Village, Teluk Ambon Sub District with 11.7 ha area. The study was conducted with the objectives for: 1) obtaining data on the physical condition of the land in the research area as the basic material in assessing the suitability of the land for horticultural crops; 2) knowing the limiting factors present in the field and can be proposed for improvement; 3) determining the land for appropriate horticultural crops. The research method was survey method with distance of transect observation. Based on the results of field observation and land evaluation, it showed that: 1) the physical condition of the land in the research area was low hilly area with the soil type of Cambisol and land cover in the form of settlements, mixed plants and shrubs, 2) Based on the results of land evaluation there were 3 main limiting factors, such as rainfall, erosion and slope, 3) Based on actual suitability, the most suitable plants to recommend for each land unit were duku and rambutan.
\end{abstract}

Keywords: evaluation, land, horticulture

\begin{abstract}
ABSTRAK
Penelitian dilaksanakan pada bulan Oktober - November 2016 di Lahan Sekolah Tinggi Theologia Maluku Dusun Kate-kate Desa Hunut Kecamatan Teluk Ambon dengan luas 11.7 ha. Penelitian ini dilaksanakan dengan tujuan: 1) memperoleh data tentang kondisi fisik lahan di daerah penelitian sebagai bahan dasar dalam menilai kesesuaian lahan untuk tanaman hortikultura, 2) mengetahui faktor-fakor pembatas yang terdapat di lapangan dan dapat diusulkan untuk perbaikan, 3) memberikan rekomendasi pemanfaatan lahan untuk tanaman hortikultura yang sesuai. Metode penelitian adalah metode survey dengan jarak observasi transek. Berdasarkan hasil pengamatan lapangan dan evaluasi lahan, hasil yang ditemukan adalah : 1) kondisi fisik lahan di daerah penelitian yaitu merupakan daerah perbukitan rendah dengan jenis tanah kambisol dan penutup lahan berupa pemukiman, kebun campuran dan semak belukar, 2) Berdasarkan hasil evaluasi lahan maka terdapat 3 faktor pembatas utama yaitu curah hujan, bahaya erosi dan kemiringan lereng, 3) Berdasarkan kesesuaian aktual terpilih rekomendasi tanaman yang paling cocok untuk tiap satuan lahan adalah tanaman duku dan rambutan.
\end{abstract}

Kata kunci: evaluasi, lahan, hortikultura

\section{PENDAHULUAN}

Kebutuhan akan lahan semakin meningkat seiring dengan pertambahan jumlah penduduk, bertambahnya jumlah penduduk berarti bertambah pula kebutuhan lahan untuk permukiman, hal tersebut akan berpengaruh terhadap penggunaan lahan yang lain seperti, lahan pertanian, perindustrian, rekreasi, pertambangan dan sebagainya. Kemudian jika ditinjau secara seksama luas lahan yang ada relatif tetap, sehingga diperlukan perencanaan dan penataan dalam menetapkan penggunaan lahan baik untuk sektor pertanian maupun non pertanian, agar lahan yang ada dapat dimanfaatkan secara efektif dan efisien dengan mempertimbangkan antara jenis penggunaan lahan, potensi lahan dan pengelolaan lahan yang akan dilakukan.

Mulyadi (1971) dalam Louhenapessy (1975), mengemukakan bahwa suatu usaha pertanian harus didasarkan pada potensi dan kemampuan wilayah untuk menjamin produktivitas dan kelestariannya, sehingga penggunaan kekayaan alam berupa sumberdaya lahan perlu diatur sebaik-baiknya agar bermanfaat untuk usaha 
dalam jangka waktu yang lama. Dengan demikian maka pemanfaatan sumberdaya lahan haruslah disesuaikan dengan kemampuannya sehingga dapat digunakan dalam jangka waktu yang lama dan berkelanjutan dengan tidak mangabaikan prinsip-prinsip ekologi untuk tetap menjaga kelestariannya. Oleh karena itu usaha-usaha evaluasi lahan perlu dilaksanakan sebagai dasar dalam perencanaan penggunaan lahan.

Sekolah Tinggi Thelogia Maluku (STTMA) merupakan salah satu perguruan tinggi yang ada di Maluku yang mempunyai luas lahan sebesar 11,7 Ha. Pada lokasi ini akan dilakukan penggarapan lahan untuk tanaman hortikultura khususnya untuk tanaman sayuran sedangkan pada lokasi tanaman buah-buahan tumbuh paling banyak dan paling baik. Pada lokasi ini secara keseluruhan belum mempunyai data khusus tentang kondisi lahan dalam hubungannya dengan kesesuaian lahan untuk tanaman hortikultura maka perlu dilakukan penelitian ini untuk evaluasi lahan guna mendapatkan kesesuaian lahan untuk tanaman hortikultura. Sehingga pembangunan pertanian dapat dilaksanakan berdasarkan kesesuaiannya.

Penelitian ini bertujuan untuk: 1) memperoleh data tentang kondisi fisik lahan di daerah penelitian untuk menilai kesesuaian lahan untuk tanaman hortikultura; 2) mengetahui faktor-faktor pembatas yang terdapat di lapangan dan dapat diusulkan untuk perbaikan; dan 3) memberikan rekomendasi pemanfaatan lahan untuk tanaman hortikultura yang sesuai.

\section{METODE PENELITIAN}

Penelitian dilaksanakan di Lahan STTMA Dusun Kate-kate Kec Teluk Ambon yang berlangsung pada tanggal 15 Oktober 2016 sampai 15 November 2016.

\section{Bahan}

Bahan dan alat yang digunakan dalam penelitian ini meliputi peta kerja lapangan skala 1 : 2.000, larutan $\mathrm{HCl}$, $\mathrm{H}_{2} \mathrm{O}_{2}$, kertas $\mathrm{pH}$ dan aquades. Global Posting System (GPS), Kompas, sekop, Abney Level, Meter, Auger (Bor), Pisau Lapang, Parang, Kartu Deskripsi Profil, buku munsel (monsel soil colour chart), pacul, dan alat tulis menulis.

\section{Metode Penelitian}

Metode yang digunakan dalam penelitian ini adalah metode survey lapangan dengan jarak observasi transek.

\section{HASIL DAN PEMBAHASAN}

\section{Gambaran Umum Daerah Penelitian}

Secara administratif daerah penelitian dalam wilayah Kota Ambon Kecamatan Teluk Ambon Propinsi
Maluku. Secara geografis lokasi penelitian berbatasan: sebelah Utara dengan Petuanan Desa Hitu, sebelah Selatan dengan Teluk Ambon Baguala, sebelah Barat dengan Petuanan Desa Poka dan sebelah Timur dengan Petuanan Desa Waiheru.

\section{Satuan Lahan}

Satuan lahan pada wilayah penelitian didasarkan pada beberapa faktor fisik lahan yaitu bentuk lahan/fisiografi, lereng dan penggunaan lahan. Atribut penyusun satuan lahan diperoleh melalui analisis beberapa peta tematik seperti peta topografi, peta penutup lahan.

\section{Bentuk lahan :}
a. Dataran rendah (plain)
b. Perbukitan rendah (Hilly) dan
c. Pengunungan (Mountain)

2. Lereng $(\%)$ :
a. $0-3 \%$ (datar) $\left(\mathrm{L}_{0}\right)$
b. $3-8 \%$ (landai) $\left(\mathrm{L}_{1}\right)$
c. $8-15 \%$ (bergelombang) $\left(\mathrm{L}_{2}\right)$
d. $15-30 \%$ (agak curam) $\left(\mathrm{L}_{3}\right)$
e. $30-45 \%$ (curam) $\left(\mathrm{L}_{4}\right)$
f. $>45 \%$ (sangat curam) $\left(\mathrm{L}_{5}\right)$

3. Penutup lahan :
a. $\mathrm{P}=$ Pemukiman
b. $\mathrm{kc}=$ Tanaman campuran
c. $\mathrm{sb}=$ Semak belukar

\section{Penilaian Kesesuaian Lahan Untuk Beberapa Jenis Tanaman Hortikultura}

Penilaian kesesuaian lahan untuk beberapa tanaman hortikultura (mangga, manggis, rambutan, duku, sawi, cabai, tomat dan nanas), dapat ditetapkan kesesuaian lahan yang sesuai pada lokasi penelitian melalui pendekatan kualitas/karakteristik lahan (terutama faktor fisik lahan) yang dilakukan untuk menetapkan kesesuaian lahan.

Kesesuaian lahan aktual adalah kesesuaian lahan berdasarkan data sifat biofisik tanah atau sumber daya lahan sebelum lahan tersebut diberikan masukanmasukan yang diperlukan untuk mengatasi kendala. Data biofisik tersebut berupa karakteristik tanah dan iklim yang berhubungan dengan persyaratan tumbuh tanaman yang dievaluasi.

Kesesuaian lahan potensial menyatakan keadaan kesesuaian lahan yang akan dicapai setelah dilakukan usaha-usaha perbaikan terhadap kualitas lahan yang merupakan faktor pembatas. Setelah kualitas lahan diperbaiki kemudian dibandingkan lagi dengan kebutuhan tanaman hortikultura (duku, mangga, manggis, rambutan, cabai, nanas, sawi dan tomat) dan kelas kesesuaian yang dicapai setelah perbaikan merupakan kesesuaian lahan potensial. 
Tabel 1. Satuan Lahan Sekolah Tinggi Theologia Maluku

\begin{tabular}{|c|c|c|c|c|c|c|c|c|}
\hline \multirow{2}{*}{$\begin{array}{l}\text { Satuan } \\
\text { Lahan }\end{array}$} & \multirow[t]{2}{*}{ Fisiografi } & \multicolumn{2}{|r|}{ Lereng } & \multirow{2}{*}{$\begin{array}{l}\text { Penggunaan } \\
\text { Lahan }\end{array}$} & \multirow{2}{*}{$\begin{array}{l}\text { Bahan } \\
\text { Induk }\end{array}$} & \multirow[t]{2}{*}{ Jenis Tanah } & \multicolumn{2}{|c|}{ Luas } \\
\hline & & $\begin{array}{c}\text { Kelas } \\
(\%)\end{array}$ & Bentuk & & & & Ha & $\%$ \\
\hline P Lop & Dataran & $0-3$ & Datar & Pemukiman & Loss mterial & Kambisol & 1,394 & 11,823 \\
\hline$P L_{2} p$ & Dataran & $8-15$ & Bergelombang & Pemukiman & Loss mterial & Kambisol & 0,764 & 6,480 \\
\hline P L $\mathbf{L}_{2} \mathrm{kc}$ & Dataran & $8-15$ & Bergelombang & $\begin{array}{c}\text { Kebun } \\
\text { campuran }\end{array}$ & Loss mterial & Kambisol & 0,691 & 5,860 \\
\hline P Lo sb & Dataran & $0-3$ & Datar & Semak belukar & Loss mterial & Kambisol & 0,737 & 6,251 \\
\hline$P \mathbf{L}_{2} \mathbf{s b}$ & Dataran & $8-15$ & Bergelombang & Semak belukar & Loss mterial & Kambisol & 3,884 & 32,940 \\
\hline $\mathrm{H} \mathrm{L}_{3} \mathbf{s b}$ & Perbukitan & $\begin{array}{c}15- \\
30\end{array}$ & Agak curam & Semak belukar & Loss mterial & Kambisol & 3,656 & 31,007 \\
\hline H L4 Sb & Perbukitan & $\begin{array}{c}30- \\
45\end{array}$ & Curam & Semak belukar & Loss mterial & Kambisol & 0,665 & 5,640 \\
\hline & & & & & & Total & 11.791 & 100 \\
\hline
\end{tabular}

Sumber: Hasil olah data lapangan

Tabel 2. Kelas Kesesuaian Lahan untuk Tanaman Hortikultura

\begin{tabular}{|c|c|c|c|c|c|c|c|c|}
\hline Tanaman & Duku & & Mangga & & Manggis & & Rambutan & \\
\hline S L & A & $\mathrm{P}$ & A & $\mathrm{P}$ & A & $\mathrm{P}$ & A & $P$ \\
\hline P Lop & S2wa,rc & $\mathrm{S} 2 \mathrm{rc}$ & Nwa & - & Nwa & - & S2wa,rc & S2rc \\
\hline$P \mathbf{L}_{2} \mathbf{p}$ & S2wa,rc,eh & S2rc & Nwa & - & Nwa & - & S2wa,rc,eh & $\mathrm{S} 2 \mathrm{rc}$ \\
\hline$P \mathrm{~L}_{2} \mathbf{k c}$ & S3eh & S2eh & Nwa & - & Nwa & - & S3eh & S2eh \\
\hline P Lo sb & S2wa,rc & $\mathrm{S} 2 \mathrm{rc}$ & Nwa & - & Nwa & - & S2wa,rc & $\mathrm{S} 2 \mathrm{rc}$ \\
\hline$P L_{2} \mathbf{s b}$ & S3eh & S2eh & Nwa & - & Nwa & - & S3eh & S2eh \\
\hline $\mathbf{H} \mathrm{L}_{3} \mathbf{s b}$ & S3eh & S2eh & Nwa & - & Nwa & - & S3eh & S2eh \\
\hline $\mathrm{H} \mathrm{L}_{4} \mathbf{S b}$ & Neh & - & Nwa,eh & - & Nwa,eh & - & S3eh & S2eh \\
\hline Tanaman & Cabai & & Sawi & & Tomat & & Nanas & \\
\hline S L & $\mathrm{A}$ & $P$ & $\mathrm{~A}$ & $\mathrm{P}$ & $\mathrm{A}$ & $P$ & $\mathrm{~A}$ & $P$ \\
\hline$P L_{0} p$ & S3wa & S2wa & Nwa & - & S3wa & S2wa & S3wa & S2wa \\
\hline$P \mathbf{L}_{2} \mathbf{p}$ & S3wa,eh & S2wa,eh & Nwa & - & S3wa,eh & S2wa,eh & S3wa,eh & S2wa,eh \\
\hline$P \mathrm{~L}_{2} \mathbf{k c}$ & S3wa,eh & S2wa,eh & Nwa & - & S3wa,eh & S2wa,eh & S3wa,eh & S2wa,eh \\
\hline P Lo sb & S3wa & S2wa & Nwa & - & S3wa & S2wa & S3wa & S2wa \\
\hline P L L $\mathbf{s b}$ & S3wa,eh & S2wa,eh & Nwa & - & S3wa,eh & S2wa,eh & S3wa,eh & S2wa,eh \\
\hline $\mathrm{H} \mathrm{L}_{3} \mathbf{s b}$ & Neh & - & Nwa,eh & - & S3wa,eh & S2wa,eh & Nwa,eh & - \\
\hline H L4 Sb & $\mathrm{Neh}$ & - & Nwa,eh & - & Neh & - & Neh & - \\
\hline
\end{tabular}

Sumber: Hasil olah data lapangan berdasarkan kriteria Petunjuk Teknis Evaluasi Lahan Untuk komoditas Pertanian.

Keterangan: $\mathrm{SL}=$ Satuan Lahan; $\mathrm{A}=$ aktual $\mathrm{P}=$ potensial

\section{Tindakan Perbaikan Tiap Faktor Pembatas}

Dalam menentukan jenis usaha perbaikan perlu diperhatikan karakteristik lahan yang menyusun masingmasing kualitas lahan. Karakteristik lahan dapat dibedakan menjadi karakteristik lahan yang dapat diperbaiki sesuai dengan tingkat pengelolaan yang akan diterapkan dan karakteristik yang tidak dapat diperbaiki. Tingkat pengelolaan menunjukan rendah, sedang atau tingginya biaya (modal) yang diperlukan sebagai implementasi usaha perbaikan yang ditetapkan.

Dari hasil kesesuaian lahan aktual untuk beberapa tanaman hortikultura diatas maka diperoleh sub kelas dimana merupakan faktor pembatas antara lain ketersediaan air (curah hujan), media perakaran (tekstur tanah) dan bahaya erosi (tingkat bahaya erosi dan kemiringan lereng).

Faktor pembatas curah hujan ini berhubungan dengan ketersediaan air bagi tanaman. Curah hujan yang tinggi dapat menyebabkan pertumbuhan dan perkembangan tanaman hortikultura terhambat. Faktor pembatas ini dapat diatasi dengan pembuatan saluran drainase.

Faktor pembatas bahaya erosi dan kemiringan lereng dapat diatasi dengan cara penanaman dengan strata tanaman yang baik yaitu dengan tanaman tingkat tinggi sampai tanaman tingkat rendah, hal ini berkaitan juga dengan penanaman secara kontur atau pertanaman lorong yang bertujuan untuk mengurangi erosi dan dapat 
melestarikan lingkungan dan juga dapat dibuat teras seri. Dalam hal ini merupakan tindakan konservasi tanah.

\section{KESIMPULAN}

Berdasarkan hasil penelitian yang telah diuraikan diatas dan sejalan dengan tujuan penelitian ini, maka dapat disimpulkan bahwa:

1. Kondisi fisik lahan di daerah penelitian adalah sebagai berikut :

- Daerah datar sampai perbukitan rendah dengan bentuk wilayah datar (0-3\%), bergelombang (8$15 \%)$, agak curam $(15-30 \%)$ dan curam (30$45 \%)$.

- Tipe iklim C1 menurut Oldeman (1975). Schmidt dan Ferguson (1951) klasifikasi iklim A yaitu sangat basah

- Jenis tanah adalah kambisol.

2. Faktor-faktor pembatas utama untuk tiap tanaman hortikultura yang terdapat di lapangan yaitu curah hujan, kemiringan lereng dan bahaya erosi
3. Berdasarkan kesesuaian aktual terpilih rekomendasi tanaman yang paling cocok untuk tiap satuan lahan adalah tanaman duku dan rambutan.

\section{DAFTAR PUSTAKA}

Djaenudin. 2000. Kriteria Kesesuaian Lahan untuk Komoditas Pertanian. Badan Penelitian dan Pengembangan Pertanian. Bogor.

Djaenudin, D. dan Basuni. 1993/1994. Materi Latihan Evaluasi Lahan. Kerjasama Balai Penelitian dan Latihan Pertanian dengan Pusat Penelitian Tanah dan Agroklimat.

Hardjowigeno, 1989. Ilmu Tanah. Mediyatama Sarana Perkasa, Jakarta.

Louhenapessy, J.E. 1975. Penetapan Pola Penggunaan Tanah Untuk Proyek Pertanian di Makariki Pulau Seram. Thesis Fakultas Pertanian/Kehutanan Universitas Pattimura Afiliasi Institut Pertanian Bogor.

Louhenapessy, J.E. 1985. Diktat Kuliah Survey Tanah dan Evaluasi Lahan. Fakultas Pertanian Universitas Pattimura. Ambon. 